\title{
De Handels- en Samenwerkingsovereenkomst tussen de EU en het VK: partnerschap of conflictbeheersing?
}

\author{
Dr. J.E. Larik en prof. dr. R.A. Wessel*
}

De Handels- en samenwerkingsovereenkomst tussen de Europese Unie (EU) (en Euratom) en het Verenigd Koninkrijk (VK) (de HSO) is ondertekend op 30 december $2020^{1}$ en op 1 mei 2021 formeel in werking getreden. ${ }^{2}$ Terwijl het Terugtrekkingsakkoord (TA) tussen de EU en het VK kan worden gezien als de 'echtscheidingsovereenkomst', die voornamelijk alle kwesties behandelt die verband houden met een ordelijke uittreding van het VK, ${ }^{3}$ legt de HSO de basis voor een nieuwe relatie tussen de twee partijen. Deze relatie is niet langer gebaseerd op een lidmaatschap dat wordt bepaald door de supranationale rechtsorde van de EU, maar op een pragmatisch partnerschap op basis van internationaal publiekrecht, of, zoals sommige Britse vertegenwoordigers blijven benadrukken, een relatie tussen 'soevereine gelijken'. ${ }^{4}$

Handels- en samenwerkingsovereenkomst tussen de Europese Unie en de Europese Gemeenschap voor Atoomenergie, enerzijds, en het Verenigd Koninkrijk van

* Dr. J.E. (Joris) Larik is universitair docent vergelijkend, EU- en internationaal recht aan de Universiteit Leiden. Prof. dr. R.A. (Ramses) Wessel is hoogleraar Europees recht aan de Rijksuniversiteit Groningen.

1 Handels- en samenwerkingsovereenkomst tussen de Europese Unie en de Europese Gemeenschap voor Atoomenergie, enerzijds, en het Verenigd Koninkrijk van Groot-Brittannië en Noord-lerland, anderzijds (PbEU 2021, L 149/10). De versie die in december 2021 gepubliceerd werd is opgeschoond en gecorrigeerd. De versie van april 2021 is de juiste versie.

Besluit (EU) 2021/689 van de Raad van 29 april 2021 betreffende de sluiting, namens de Unie, van de Handels- en samenwerkingsovereenkomst tussen de Europese Unie en de Europese Gemeenschap voor Atoomenergie, enerzijds, en het Verenigd Koninkrijk van Groot-Brittannië en Noord-lerland, anderzijds, en van de Overeenkomst tussen de Europese Unie en het Verenigd Koninkrijk van Groot-Brittannië en Noord-lerland inzake beveiligingsprocedures voor de uitwisseling en bescherming van gerubriceerde gegevens (PbEU 2021, L 149/2). Voor de inwerkingtreding op 1 mei 2021 werd de HSO voorlopig toegepast.

3 R.A. Wessel \& J.E. Larik, 'Brexit means Brexit? De stand van zaken na de uittreding', SEW 2020, afl. 6, p. 258.

4 In het origineel: 'sovereign equals', Prime Minister's statement on EU negotiations, 24 december 2020, (beschikbaar via www.gov.uk/government/ speeches/prime-ministers-statement-on-eu-negotiations-24-december-2020).
Groot-Brittannië en Noord-Ierland, anderzijds (PbEU 2021, L 149/10).

Besluit (EU) 2021/689 van de Raad van 29 april 2021 betreffende de sluiting, namens de Unie, van de Handels- en samenwerkingsovereenkomst tussen de Europese Unie en de Europese Gemeenschap voor Atoomenergie, enerzijds, en het Verenigd Koninkrijk van Groot-Brittannië en Noord-Ierland, anderzijds, en van de Overeenkomst tussen de Europese Unie en het Verenigd Koninkrijk van Groot-Brittannië en Noord-Ierland inzake beveiligingsprocedures voor de uitwisseling en bescherming van gerubriceerde gegevens (PbEU 2021, L 149/2).

Ondanks het feit dat artikel 50 Verdrag betreffende de Europese Unie (VEU) in een gecombineerd proces van terugtrekking en regulering van toekomstige betrekkingen voorziet, ${ }^{5}$ drong de Unie erop aan dat er geen onderhandelingen over de toekomstige betrekkingen zouden worden begonnen voordat overeenstemming was bereikt over de terugtrekkingsregelingen. Het gehele proces duurde vier jaar, vanaf de kennisgeving door het VK van zijn voornemen om uit de EU te stappen op 29 maart 2017 tot de volledige inwerkingtreding van de HSO tussen de EU en het VK, bijna vijf jaar na het Brexitreferendum van 23 juni $2016 .{ }^{6}$

Op basis van art. 50 lid 2 VEU 'sluit de Unie na onderhandelingen met deze staat een akkoord over de voorwaarden voor zijn terugtrekking, waarbij rekening wordt gehouden met het kader van de toekomstige betrekkingen van die staat met de Unie'. Inderdaad is eerder al gewezen op het feit dat deze bepaling in de richting wijst van 'a single comprehensive agreement (...) which is supposed to regulate not only the departure but also future European Union-departing country relations'. Zie A. Łazowski, 'Withdrawal from the European Union and Alternatives to Membership', European Law Review 2012, 37, p. 537. Nu zowel het TA als de HSO gesloten is als 'EU-only' akkoorden, was dit inderdaad mogelijk geweest.

6 Zie A. Łazowski, 'Mind the Fog, Stand Clear of the Cliff! From the Political Declaration to the Post-Brexit EU-UK Legal Framework - Part I', European Papers 2020, 5, p. 1105; S. Usherwood, "'Our European Friends and Partners"? Negotiating the Trade and Cooperation Agreement', Journal of Common Market Studies 2021, 59, p. 115; en ook S. Fella, 'The UK-EU Trade 
Deze bijdrage heeft tot doel de nieuwe samenwerking nader te duiden op basis van een overzicht van de HSO en door deze te situeren binnen het bredere, nieuwe rechtsgebied dat de betrekkingen tussen de EU en het VK na Brexit regelt. ${ }^{7}$ Wij stellen voor dit nieuwe gebied de naam 'post-Brexitrecht' te geven. Dit artikel analyseert achtereenvolgens de juridische aard, de status en de materiële inhoud van de HSO. Dit wordt gevolgd door een analyse en duiding van de governance-bepalingen, met inbegrip van geschillenbeslechting. Het artikel sluit af met een samenvatting van de belangrijkste bevindingen en een blik op de toekomst.

\section{Structuur, aard en plaats van de HSO binnen het post-Brexitrecht}

Het doel van dit deel is om een kort overzicht te geven van de achtergrond en de structuur van de HSO. Dit wordt gevolgd door een analyse van de rechtsgrondslag onder het EU-recht en de implicaties van de keuzes die daarbij zijn gemaakt. Ten slotte zal de positie van de HSO in de context van het bredere post-Brexit juridische kader van de betrekkingen tussen de EU en het VK worden toegelicht.

\section{Structuur van de HSO en de gevolgen ervan in de} Unie-rechtsorde

In uitgeprinte versie vormt de HSO een indrukwekkende stapel papier. In de Nederlandstalige versie bevat het akkoord in totaal 1449 pagina's. ${ }^{8}$ De 783 artikelen zijn verdeeld over zeven delen. De overeenkomst bevat 49 bijlagen en drie protocollen: een protocol betreffende administratieve samenwerking en bestrijding van fraude op het gebied van belasting over de toegevoegde waarde en betreffende wederzijdse bijstand bij de invordering van schuldvorderingen met betrekking tot belastingen en heffingen; een protocol betreffende wederzijdse administratieve bijstand in douanezaken; en een protocol betreffende de coördinatie van de sociale zekerheid. Naast het grondgebied van het VK en de EU is het van toepassing op Guernsey, Jersey en het eiland Man, maar niet op Gibraltar of andere overzeese gebiedsdelen. ${ }^{9}$ Omdat Gibraltar via het VK deel uitmaakte van het EU-grondgebied is het van belang de huidige

and Cooperation Agreement: The Path to the Deal', UK House of Commons Library Briefing Paper, nr. 09101, 24 december 2020.

7 Een uitgebreidere versie van dit artikel zal later dit jaar in het Engels verschijnen als J.E. Larik \& R.A. Wessel, 'The EU-UK Post-Brexit Trade Agreement: Forging Partnership or Managing Rivalry?', in: A. Cygan \& A. Łazowski (red.), Research Handbook on Legal Aspects of Brexit, Cheltenham: Edward Elgar Publishing 2022. Zie ook S. Peers, 'So close, yet so far: The EU/UK Trade and Cooperation Agreement', Common Market Law Review 2022, 59, p. 49.

8 De bijlagen beginnen op pagina 996. Art. 780 HSO bepaalt dat, naast het Engels, alle EU-talen authentiek zijn.

9 Zie ook M. Konstantinidis \& V. Poula, 'From Brexit to Eternity: The Institutional Landscape under the EU-UK Trade and Cooperation Agreement', European Law Blog, 14 januari 2021 (beschikbaar via https://europeanlawblog. onduidelijke status zo spoedig mogelijk te regelen zodat het vrij verkeer met Spanje niet verstoord wordt. De betreffende regelingen zullen worden vastgelegd in een speciaal verdrag tussen de EU en het VK, waarover de onderhandelingen in oktober 2021 zijn begonnen. ${ }^{10}$

De HSO is meer dan een vrijhandelsovereenkomst over economische, sociale, milieu- en visserijkwesties. Het stelt onder meer ook een nieuw kader vast voor rechtshandhaving en justitiële samenwerking in strafzaken. Bovendien erkent het de noodzaak van nauwe samenwerking tussen de nationale politie en de justitiële autoriteiten, met name voor de bestrijding en vervolging van grensoverschrijdende misdaad en terrorisme.

Wat het toepasselijke rechtsstelsel betreft, onderstreept artikel 4 HSO het internationaalrechtelijke karakter van de overeenkomst en benadrukt het dat het niet voorziet in een verplichting 'om de bepalingen ervan in overeenstemming met het interne recht van een van beide Partijen uit te leggen'. Bovendien is 'een uitlegging van deze overeenkomst of van een aanvullende overeenkomst door de rechter van een van beide Partijen (...) niet bindend voor de rechter van de andere Partij'. Dit maakt duidelijk, ongetwijfeld op initiatief van het VK, dat eventuele interpretaties van de HSO door het Hof van Justitie van de Unie niet bindend zijn voor het VK; iets dat wordt bevestigd door de bepaling dat er naar nationaal recht geen vorderingsrecht bestaat in geval van schending van de overeenkomst. ${ }^{11}$ Het internationaalrechtelijke karakter van de overeenkomst is ook zichtbaar in de uitdrukkelijke afwezigheid van rechtstreekse werking van de bepalingen ervan, met uitzondering van de bepalingen over justitiële samenwerking in strafzaken (alleen binnen de EU-rechtsorde): ${ }^{12}$

'Onverminderd artikel SSC.67 van het Protocol betreffende de coördinatie van de sociale zekerheid[13] en, waar het de Unie betreft, met uitzondering van deel drie van deze overeenkomst, $\left[{ }^{14}\right]$ wordt niets in deze overeenkomst of eventuele aanvullende overeenkomsten aldus uitgelegd dat daarbij aan personen rechten worden toegekend of verplichtingen worden opgelegd, anders dan die welke tussen de Partijen uit hoofde van internationaal publiekrecht in het leven zijn geroepen, of aldus uitgelegd dat op deze overeenkomst of eventuele aanvullende overeenkomsten

eu/2021/01/14/from-brexit-to-eternity-the-institutional-landscapeunder-the-eu-uk-trade-and-cooperation-agreement/).

10 Zie uitgebreid over de post-Brexitstatus van Gibraltar, J. Santos Vara, 'The implications of the Withdrawal Agreement for Gibraltar: Is Spain taking back control?', in: J. Santos Vara \& R.A. Wessel (red.), The Routledge Handbook on the International Dimension of Brexit, London: Routledge 2021, p. 303. 11 Art. 5 lid 2 HSO

12 Dit is waar 'met uitzondering van deel drie van deze overeenkomst' in art. 5 lid 1 HSO op doelt.

13 Deze bepaling bevat een verplichting voor de partijen om ervoor te zorgen dat rechtspersonen of natuurlijke personen de bepalingen van het protocol kunnen inroepen voor nationale rechtbanken, tribunalen en administratieve autoriteiten en dat hun rechten worden beschermd.

14 Deel Drie bevat de bepalingen inzake rechtshandhaving en judiciële samenwerking in strafzaken. 
een rechtstreeks beroep kan worden gedaan binnen de interne rechtsorden van de Partijen.' ${ }^{15}$

Het is duidelijk dat dit een fundamentele verandering is in de relatie tussen de EU en het VK, aangezien een van de kenmerken van het EU-recht is dat het niet alleen recht is tussen de lidstaten, maar ook binnen die staten. En ook wanneer rechtstreekse werking niet zo duidelijk zou zijn uitgesloten, dan nog is het Hof van Justitie altijd terughoudend geweest om rechtstreekse werking te verlenen aan bepalingen waarop individuen in partnerlanden zich niet konden beroepen. ${ }^{16}$ Tegelijkertijd blijft het ontbreken van rechtstreekse werking (afgezien van de bovengenoemde uitzonderingen) opmerkelijk, ${ }^{17}$ aangezien het akkoord gaat over de relatie met een voormalige EU-lidstaat. Bovendien is er wel sprake van rechtstreekse werking van het $\mathrm{TA},{ }^{18}$ en wordt dit ook aanvaard voor bepaalde bepalingen van een aantal internationale overeenkomsten met andere staten, zoals de PSO met Rusland ${ }^{19}$ of de associatieovereenkomst met Turkije. ${ }^{20}$ Het VK is daarmee toegevoegd aan een lijst met Oekraïne, Moldavië en Georgië. ${ }^{21}$

\section{Wettelijke basis en aard van de HSO}

In plaats van 'partnerschap'22 is gekozen voor de misschien wat oppervlakkige term 'samenwerking'. Toch stelde de Europese Commissie:

'Hoewel de handels- en samenwerkingsovereenkomst niet in de buurt komt van het niveau van economische integratie dat bestond toen het VK een EU-lidstaat was, gaat zij een stuk verder dan traditionele vrijhandelsovereenkomsten en biedt zij een solide basis voor het behoud van onze al lang bestaande vriendschap en samenwerking. ${ }^{23}$

En overeenkomstig artikel 1 HSO heeft de overeenkomst tot doel de grondslag te leggen voor:

15 Art. 5 lid 1 HSO.

16 Zie R.A. Wessel \& J.E. Larik (red.), EU External Relations Law: Text, Cases and Materials, Oxford: Hart Publishing 2020, p. 156-161.

17 Łazowski heeft erop gewezen dat dit niet automatisch impliceert dat ook de toepassing van andere handhavingsdoctrines (indirecte werking en staatsaansprakelijkheid) uitgesloten is. Zie Łazowski 2020, p. 1125.

18 Art. 4 TA bepaalt: 'De bepalingen van dit akkoord en de bepalingen van het recht van de Unie die krachtens dit akkoord van toepassing zijn geworden, hebben ten aanzien van en in het Verenigd Koninkrijk dezelfde rechtsgevolgen als in de Unie en haar lidstaten. Dienovereenkomstig kunnen natuurlijke personen of rechtspersonen zich met name rechtstreeks beroepen op de in dit akkoord opgenomen of bedoelde bepalingen die voldoen aan de voorwaarden voor rechtstreekse werking krachtens het recht van de Unie.'

19 HvJ 12 april 2005, C-265/03, ECLI:EU:C:2005:213 (Simutenkov).

20 HvJ 20 september 1990, C-192/89, ECLI:EU:C:1990:322 (Sevince).

21 Zie Łazowski 2020, p. 1125

22 De term 'partnerschap' wordt slechts genoemd in de Preambule van de HSO: 'Erkennend dat er behoefte is aan een ambitieus, breed en evenwichtig economisch partnerschap (...)' en komt terug in de naam van enkele verdragsorganen (de Partnerschapsraad, het Comité voor handelspartnerschap en de Partnerschapsassemblee).

23 De Handels- en samenwerkingsovereenkomst tussen de EU en het VK: De Europese belangen beschermen, voor eerlijke mededinging zorgen en de samenwerking op gebieden van wederzijds belang voortzetten (beschikbaar via https://ec.europa.eu/info/strategy/relations-non-eu-countries/ relations-united-kingdom/eu-uk-trade-and-cooperation-agreement_nl). 'uitgebreide betrekkingen tussen de Partijen, binnen een ruimte van welvaart en goed nabuurschap die wordt gekenmerkt door nauwe en vreedzame betrekkingen op basis van samenwerking, met eerbiediging van de autonomie en soevereiniteit van de Partijen.'

Er blijft echter onenigheid tussen de EU en het VK bestaan over de aard van de HSO. Terwijl Britse leiders, onder verwijzing naar de EU-Canada-handelsovereenkomst CETA, de HSO graag een 'comprehensive Canada style free trade deal' noemen, ${ }^{24}$ is zij vanuit EU-perspectief een 'associatieovereenkomst' en valt zij daarmee binnen een bijzondere categorie EU-akkoorden. Associatieovereenkomsten hebben een nauwe relatie tussen de EU en bepaalde derde landen tot doel met samenwerking de niet alleen het economische domein bestrijkt. De EU heeft zulke associaties met tal van buurlanden zoals Oekraïne en Turkije, maar ook met verder weg gelegen landen zoals Chili.

In het besluit van de Raad tot sluiting van de $\mathrm{HSO}^{25}$ worden de rechtsgrondslagen in het Verdrag betreffende de werking van de Europese Unie (VWEU) voor de overeenkomst duidelijk opgesomd: 'met name artikel 217, in samenhang met artikel 218, lid 6, en artikel 218, lid 8, tweede alinea'. Artikel 217 VWEU bepaalt:

'De Unie kan met één of meer derde landen of internationale organisaties akkoorden sluiten waarbij een associatie wordt ingesteld die wordt gekenmerkt door wederkerige rechten en verplichtingen, gemeenschappelijk optreden en bijzondere procedures.'

Deze formulering wordt weerspiegeld in artikel 1 HSO:

'Deze overeenkomst legt de grondslag voor uitgebreide betrekkingen tussen de Partijen, binnen een ruimte van welvaart en goed nabuurschap die wordt gekenmerkt door nauwe en vreedzame betrekkingen op basis van samenwerking, met eerbiediging van de autonomie en soevereiniteit van de Partijen.'

Artikel 217 VWEU kon als rechtsgrondslag ook al worden gevonden in het besluit van de Raad betreffende de ondertekening, samen met de relevante procedurele rechtsgrondslagen (art. 218 lid 5 en 8 VWEU). ${ }^{26}$ Dit laatste is belangrijk omdat het verwijst naar de noodzaak van unanimiteit in het geval van associatieovereenkomsten (als een van de uitzonderingen op de algemene regel van stemming met gekwalificeerde meerderheid voor het sluiten van internationale overeenkomsten). Hoogstwaarschijnlijk om politieke redenen ontbreekt de term 'associatieovereenkomst' echter in de titel van de HSA. Dit wil niet zeggen dat het VK vanaf het begin tegen een associatieovereenkomst was. In de politieke verklaring werd eerder vermeld dat the overarching

Prime Minister's statement 2020; zie ook J. Portes, 'A Canada-style trade deal', UK in a Changing Europe 15 december 2020 (beschikbaar via https:// ukandeu.ac.uk/a-canada-style-trade-deal/).

25 Besluit van de Raad 2021/689 van 29 april 2021.

26 
institutional framework could take the form of an Association Agreement'. ${ }^{27}$ Nog interessanter is dat het VK geen problemen had met het aangaan van associaties met andere landen dan de EU. In de woorden van Łazowski: 'Some of the newly concluded agreements create a formal association between the UK and the EU's neighbours. So, as of 1 January 2021, the United Kingdom is formally in association with, for instance, Egypt.'28

Vanuit het perspectief van het EU-recht is de HSO dan ook een associatieovereenkomst. ${ }^{29}$ Artikel 217 VWEU verwijst niet naar andere vormen van samenwerking, ongeacht het feit dat - uiteraard - de inhoud en beleidsterreinen die onder de overeenkomst vallen niet vooraf zijn bepaald door deze rechtsgrondslag, waardoor deze enige flexibiliteit krijgt. Voorbeelden van internationale overeenkomsten op basis van artikel 217 VWEU waarin de term 'associatie' niet wordt gebruikt, zijn zeldzaam, maar de HSO is in dit opzicht niet volledig uniek. ${ }^{30}$ Een duidelijk voordeel van de keuze voor artikel 217 VWEU is het uitgebreide toepassingsgebied, waardoor wordt voorkomen dat verschillende rechtsgrondslagen voor de verschillende beleidsterreinen onder de overeenkomst vallen. Uiteraard heeft dit op zijn beurt complexe debatten met de lidstaten over de verdeling van bevoegdheden op de verschillende beleidsterreinen voorkomen. Even interessant is het feit dat de overeenkomst is gesloten als een overeenkomst die alleen voor de EU geldt, terwijl associatieovereenkomsten, vanwege hun brede reikwijdte, doorgaans worden gesloten als gemengde akkoorden. ${ }^{31}$ De Commissie stelde in dit verband:

'the exercise of Union competence through the Trade and Cooperation Agreement is in accordance with the respective competences of the Union and of the Member States. This is without prejudice to any ongoing or future negotiations for, or signature or conclusion of, international agreements with any other third country.' ${ }^{32}$

De laatste zin is duidelijk bedoeld om de lidstaten gerust te stellen dat hier niet automatisch een 'ERTA-effect' wordt veroorzaakt. Het naar een rechtszaak uit 1971 be-

27 Zie punt 120 van de Politieke Verklaring.

28 Łazowski 2020, p. 1123.

29 Zie over de betekenis hiervan bijvoorbeeld P. Van Elsuwege \& M. Chamon, The Meaning of 'Association' under EU Law: A Study on the Law and Practice of EU Association Agreements, study for the AFCO Committee, European Parliament 2019, PE 608.861.

30 Een recent voorbeeld is de partnerschapsovereenkomst tussen de leden van de groep van staten in Afrika, het Caribisch gebied en de Stille Oceaan, enerzijds, en de Europese Gemeenschap en haar lidstaten, anderzijds, ondertekend in Cotonou op 23 juni 2000 (PbEU 2000, L 317/3 (zie in verband hiermee het meest recente Besluit (EU) 2017/435 van de Raad van 28 februari 2017 (PbEU 2017, L 67/31)).

31 Een bekende uitzondering is de Stabilisatie- en associatieovereenkomst met Kosovo, die alleen door de EU is gesloten vanwege de niet-erkenning van de onafhankelijkheid van Kosovo door vijf EU-lidstaten. Zie P. Van Elsuwege, 'Legal Creativity in EU External Relations: The Stabilisation and Association Agreement between the EU and Kosovo', European Foreign Affairs Review 2017, 22, p. 393.

32 Zie 'Statement by the Commission on Article 4 of the Decision on signing'; Communication CM 5525/20, Brussel, 29 december 2020. noemde 'ERTA-effect' houdt in dat het volkenrechtelijk optreden van de lidstaten in geen geval EU-wetgeving mag aantasten. ${ }^{33}$ De Commissie maakt daarom duidelijk dat het feit alleen dat de Unie in het geval van de HSO een aantal beleidsterreinen op een 'exclusieve' manier behandelt de lidstaten niet zal kunnen weerhouden om in andere, toekomstige internationale overeenkomsten op die gebieden op te treden. ${ }^{34}$ De keuze voor een 'EU-only'-overeenkomst is in lijn met het advies van de juridische dienst van de Raad, die stelde dat alle beleidsterreinen in de HSO onder de exclusieve of gedeelde bevoegdheden van de Unie vallen:

'While not entering into a detailed examination of its different Titles and provisions, a rapid examination of the Trade and Cooperation Agreement shows that no situation of obligatory mixity arises: the EU has competence in all the fields covered by it. ${ }^{35}$

De juridische dienst stelt dat dit zelfs geldt voor gebieden van gedeelde bevoegdheden die nog niet door de Unie zijn uitgeoefend (zoals bijvoorbeeld luchtvaart-verkeersrechten). Om de lidstaten gerust te stellen, heeft de juridische dienst echter onderstreept dat:

'the fact that the Council has decided to opt, in the specific case of the Trade and Cooperation Agreement with the UK, for an EU-only agreement does not prevent Member States from continuing to exercise their national competences vis-à-vis other third countries in that same area of potential EU competence. ${ }^{36}$

Besluit 2020/2252 van de Raad wijst inderdaad op de bijzondere context, die de keuze voor een 'EU-only' akkoord rechtvaardigt:

'Gezien de uitzonderlijke en unieke aard van de handels- en samenwerkingsovereenkomst, die bestaat in een brede overeenkomst met een land dat zich heeft teruggetrokken uit de Unie, besluit de Raad hierbij gebruik te maken van de mogelijkheid dat de Unie haar externe bevoegdheid ten aanzien van het Verenigd Koninkrijk uitoefent. ${ }^{37}$ cente korte analyse: G. Butler \& R.A. Wessel, 'Happy Birthday ERTA! 50 Years of the Implied External Powers Doctrine in EU Law', European Law Blog 31 maart 2021.

34 Zie ook de verklaringen van de Commissie en twee lidstaten (Oostenrijk en Cyprus) in bijlage bij Besluit 2020/2252 van de Raad, mededeling CM $5525 / 20$ van de Raad van de Europese Unie van 29 december 2020, p. 7. Zie recent hierover I. Govaere, 'Implied Powers of the EU, Limits to Political Expediency, and Internationally Inspired Pragmatism: Commission v Council (ERTA)', in: G. Butler \& R.A. Wessel (red.), EU External Relations Law: The Cases in Context, Oxford: Hart Publishing 2022.

35 The Brexit deal - Council legal service opinion, EU Law Analysis 27 januari 2021 (beschikbaar via http://eulawanalysis.blogspot.com/2021/01/thebrexit-deal-council-legal-service.html). Nadruk in het origineel.

36 The Brexit deal-Council legal service opinion 2021, punt 38.

37 Overweging 6 van Besluit (EU) 2020/2252 van de Raad. 


\section{De plaats van de HSO in 'post-Brexitrecht'}

Zoals Van Elsuwege opmerkt, vormt de HSO '(...) only the core of a rather sophisticated legal structure defining the future bilateral relations between the EU and the UK. ${ }^{38}$ Het 'post-Brexitrecht' is zowel breder als dieper dan de HSO en omvat zowel huidige als toekomstige regelingen.

Wat betreft de post-Brexit juridische betrekkingen tussen de EU en het VK die verder gaan dan de HSO, is het goed te wijzen op het feit dat de EU en het VK simultaan ook akkoorden hebben gesloten over een veilige uitwisseling van gegevens ${ }^{39}$ en over veilig en vreedzaam gebruik van kernenergie, om de gevolgen van de terugtrekking van het VK uit de Europese Gemeenschap voor Atoomenergie op te vangen. ${ }^{40}$

Bovendien mag niet worden vergeten dat het TA van kracht blijft. Terwijl sommige onderdelen daarvan (bijvoorbeeld over de overgangsperiode ${ }^{41}$ ) niet meer relevant zijn, blijven andere van toepassing of zijn ze pas aan het einde van de overgangsperiode in werking getreden. Zo blijft het Hof van Justitie een rol spelen (zie verder hieronder). Bovendien is het aan het TA gehechte Noord-Ierse Protocol (NIP) voor onbepaalde tijd van toepassing, tenzij de instemming ermee wordt ingetrokken door de Noord-Ierse Assemblee, die daartoe pas na vier jaar de eerste mogelijkheid heeft (zonder dat overigens duidelijk is wat dan de oplossing voor de Ierse grens zou zijn). ${ }^{42}$

Het TA verwijst impliciet naar de HSO als een van de overeenkomsten met betrekking tot remedies voor niet-naleving. In geval van langdurige niet-naleving staat het TA de klagende partij toe om verplichtingen op te schorten, niet alleen van het TA zelf (met het deel over burgerrechten als belangrijke uitzondering), maar ook van 'delen van een [sic] enig ander akkoord tussen de Unie en het Verenigd Koninkrijk onder de in dat akkoord vervatte voorwaarden'. ${ }^{43}$ Daarom kan voor geschillenbeslechting onder het TA, de HSO (met inbegrip van de bepalingen over markttoegang) worden gebruikt om naleving van het TA, met inbegrip van het NIP, aan te moedigen (zie ook hieronder).

Bovendien worden de betrekkingen tussen het VK en de EU nog steeds bepaald door andere internationale verplichtingen die beide partijen binden en waarnaar de HSO verwijst. Het gaat onder meer om de Overeenkomst van Parijs, het Europees Verdrag voor de Rechten van de

P. Van Elsuwege, 'A New Legal Framework for EU-UK Relations: Some Reflections from the Perspective of EU External Relations Law', European Papers 2020, 6, p. 787; en Łazowski 2020.

39 Overeenkomst tussen de Europese Unie en het Verenigd Koninkrijk van Groot-Brittannië en Noord-lerland inzake beveiligingsprocedures voor de uitwisseling en bescherming van gerubriceerde gegevens (PbEU 2021 L 149/2540).

40 Overeenkomst tussen de regering van het Verenigd Koninkrijk van Groot-Brittannië en Noord-lerland en de Europese Gemeenschap voor Atoomenergie betreffende samenwerking inzake het veilige en vreedzame gebruik van kernenergie (PbEU 2021, L 150/1).

41 Art. 126-132 TA.

42 Zie C. Harvey, 'The Irish Border', in: F. Fabbrini (red.), The Law and Politics of Brexit - Volume II: The Withdrawal Agreement, Oxford: Oxford University Press 2020, p. 148.

43 Art. 178 lid 2 onder b HSO.
Mens, verschillende WTO-overeenkomsten zoals de GATT 1994, en UNCLOS. ${ }^{44}$

'Post-Brexitrecht' gaat ook dieper dan de HSO en ander relevant internationaal recht. Het heeft ook een duidelijke nationaalrechtelijke dimensie. Voor het VK geldt dat internationale overeenkomsten, om effecten teweeg te brengen in de Britse rechtsorde, door middel van parlementaire handelingen in het nationale recht worden opgenomen. In het geval van de HSO gebeurde dit via de European Union (Future Relationship) Act 2020, die aansloot bij andere Brexit-gerelateerde Britse wetgeving. Bovendien is het EU-recht, dat van toepassing blijft in het Britse rechtssysteem via de European Union (Withdrawal) Act van 2018, relevant voor de werking van de HSO, met name wat betreft toekomstige verschillen in regelgeving en de mogelijkheid van maatregelen om het evenwicht te herstellen.

Binnen de EU maakt de HSO echter direct deel uit van het EU-recht vanwege het meer monistische rechtssysteem ${ }^{45}$ en de HSO staat, samen met het andere internationale recht dat de EU bindt, binnen de normenhiërarchie onder het primaire EU-recht, maar boven het secundaire recht. Eenzijdige wettelijke besluiten van de EU zijn van bijzonder belang voor de toegang van het VK tot de EU-markt en de samenwerking met EU-instellingen en -agentschappen. Te denken valt aan besluiten over gegevensbescherming of financiële diensten die vaststellen of het Britse beschermingsniveau hiervoor voldoende is.

Ten slotte is het 'post-Brexitrecht' nog werk in uitvoering. De HSO erkent dit, aangezien Deel Een onder meer ingaat op het idee dat latere bilaterale overeenkomsten tussen de EU en het VK in beginsel 'aanvullende overeenkomsten' vormen op de HSO en een 'integraal onderdeel' zullen vormen van het algemene kader. ${ }^{46}$ De HSO is daarom veel meer dan een enkele bilaterale overeenkomst; het moet de 'raamovereenkomst' worden voor de toekomstige relatie tussen de EU (en Euratom) en het VK. Gezien de ervaring met het ontbreken van een overkoepelende overeenkomst in de betrekkingen tussen de EU en Zwitserland, ${ }^{47}$ wilde de Europese Raad wellicht vanaf het begin een basis hebben voor een relatie tussen de EU en het VK die zou lijken op andere alomvattende associaties of partnerschappen met andere landen, waaronder een meerderheid van de buurlanden van de EU. ${ }^{48}$ Het karakter van de HSO is echter innovatief in die zin dat het zowel een overeenkomst is met gedetailleerde bepalingen over bijvoorbeeld handel, vervoer en visserij als het kader voor toekomstige overeenkomsten tussen de EU en het VK.

Zie art. 401, 764 en 772 lid 4 HSO (verwijzend naar de Overeenkomst van Parijs over klimaatverandering); art. 19, 20, 26, 30, 32, 33, 218 lid 3, 272, 378, 412, 512 en 514 (verwijzend naar de Algemene Overeenkomst betreffende tarieven en handel (GATT 1994)); en art. 404 lid 2 onder a, 493 , 495 en 520 lid 2 HSO (verwijzend naar het VN-Zeerechtverdrag).

45 Art. 216 lid 2 VWEU.

46 Art. 2 HSO.

47 Als gesuggereerd door Van Elsuwege 2021, p. 788.

48 Zie de richtlijnen van de Europese Raad (art. 50 VEU), Brussel, 23 maart 2018, EUCO XT 20001/18. 
Mocht ook de nieuwe relatie mislopen, dan staat uiteindelijk artikel 779 HSO de beëindiging van de overeenkomst door elke (individuele) partij toe door middel van een schriftelijke kennisgeving, waarna de 'overeenkomst en aanvullende overeenkomsten vervallen op de eerste dag van de twaalfde maand na de datum van kennisgeving'. Naast deze ingrijpende oplossing kan de overeenkomst ook worden herzien. Dit kan via een formele herzieningsprocedure, maar in bepaalde gevallen ook via besluiten van de HSO-bestuursorganen. ${ }^{49}$

\section{Het materiële recht in de HSO}

Terwijl sommige elementen in de HSO innovatief zijn, zijn andere onderdelen vergelijkbaar met bestaande handelsovereenkomsten die door de EU zijn gesloten, zoals CETA met Canada en de economische partnerschapsovereenkomst met Japan. ${ }^{50}$ Deze paragraaf beschrijft de materiële inhoud van de HSO onder de koppen handel en economische samenwerking (de ' $\mathrm{H}$ ' in de HSO), overige, niet-economische samenwerking (de ' $\mathrm{S}$ ' in de HSO), alsmede relevante inhoudelijke thema's die niet erin zijn opgenomen.

\section{De 'H' van de HSO: Handel en economische samenwerking}

Deel twee van de HSO tussen de EU en het VK over 'Handel, vervoer, visserij en andere regelingen' is de kern van

de economische samenwerking tussen de EU en het VK na Brexit. Voor de handel in goederen garandeert de HSO in beginsel wederzijdse markttoegang zonder invoerrechten of contingenten. Dit betekent echter niet het vrije verkeer van goederen zoals het VK dit voorheen als lidstaat gewend was. Nu moet bijvoorbeeld aan vereisten wat betreft oorsprongsregels worden voldaan om voor de preferentiële behandeling in aanmerking te komen; anders kunnen alsnog tarieven worden toegepast. Ook ander extra papierwerk is nu nodig, bijvoorbeeld op het gebied van conformiteitsbeoordeling. Volgens schattingen leidt dit tot miljarden euro's aan extra kosten voor bedrijven. ${ }^{51}$

Op het gebied van handel in diensten voorziet de HSO in de nationale behandeling van dienstverleners en een

49 Art. 776 HSO. Opvallend is dat de beëindiging van sommige delen van de overeenkomst gevolgen zal hebben voor andere delen, met name wanneer 'essentiële onderdelen' van de overeenkomst op het spel staan of in het specifieke geval van een beëindiging van het visserijdeel, dat zou leiden tot het einde van de bepalingen inzake handel en luchtvaart (zie ook art. 509 HSO). Bovendien kan schorsing van bepalingen uit de HSO deel uitmaken van corrigerende maatregelen op het gebied van lucht- of wegvervoer. Zie verder Łazowski 2020, p. 1126-1127.

50 Brede Economische en Handelsovereenkomst (CETA) tussen Canada, enerzijds, en de Europese Unie en haar lidstaten, anderzijds (PbEU 2017, L 11/23); Overeenkomst tussen de Europese Unie en Japan betreffende een economisch partnerschap (PbEU 2018, L 330/3).

51 Y.Ayele, M. Gasiorek, P. Holmes, A. Jerzewska \& S. Walmsley, 'Taking Stock of the UK-EU Trade and Cooperation Agreement: Trade in Goods. Briefing Paper 52', UK Trade Policy Observatory briefing paper nr. 52, januari 2021 (beschikbaar via https://blogs.sussex.ac.uk/uktpo/files/2021/01/Briefingpaper-52.pdf). meestbegunstigingsclausule. ${ }^{2}$ Voor de erkenning van beroepskwalificaties is er echter slechts een algemeen kader. ${ }^{53}$ De HSO garandeert bovendien de nationale behandeling van investeerders en een meestbegunstigingsclausule voor vestiging en activiteiten van investeerders. ${ }^{54}$

Op het gebied van financiële diensten, een onderwerp van groot belang voor het VK vanwege Londen als mondiaal knooppunt voor de financiële sector, voorziet de HSO slechts in algemene verplichtingen. Enerzijds geeft dit de Britse regering meer ruimte voor afwijkende regelgeving; ${ }^{55}$ anderzijds hebben in het VK gevestigde financiële instellingen hun 'paspoortrechten', waarmee ze in de hele EU hun diensten mochten aanbieden, verloren.

Belangrijk en innovatief zijn de bepalingen in deel twee over het 'gelijke speelveld' (level playing field). ${ }^{56}$ Terwijl andere externe overeenkomsten, zoals de associatieovereenkomst tussen de EU en Oekraïne, bepalingen bevatten over onderlinge aanpassing van de regelgeving op sommige gebieden, ${ }^{57}$ is het hoofdstuk over gelijk speelveld in de HSO ongekend wat betreft zijn doel (het beoogt het inperken van divergentie in plaats van convergentie van regelgeving), detailniveau en handhavingsmechanismen. Dit komt voort uit de bezorgdheid van de EU over het feit dat het VK een (volgens de EU) oneerlijk concurrentievoordeel zou kunnen verwerven door versoepeling van regelgeving.

Het gedeelte over het gelijk speelveld gaat onder meer over mededingingsregels, subsidies, arbeids- en sociale normen en milieu en klimaat. In algemene bewoordingen bevestigt de HSO het recht op eigen regelgeving ('right to regulate'), maar ze verplicht de partijen ook tot 'non-regressie'. Dit laatste houdt in dat een partij haar beschermingsniveau niet onder de niveaus die aan het einde van de overgangsperiode van kracht waren zodanig mag verlagen 'op een wijze die van invloed is op de handel of de investeringen tussen de Partijen, onder meer doordat zij haar wetgeving en normen niet doeltreffend handhaaft'. ${ }^{58}$ In geval van divergentie van regelgeving met een dergelijk effect kan de andere partij evenwichtsherstellende maatregelen nemen, die op hun beurt door de divergerende partij kunnen worden aangevochten door middel van arbitrage. Het verschil tus-

52 Art. 137-138 HSO.

53 Art. $158 \mathrm{HSO}$.

54 Art. 129-130 HSO.

55 J. Marchsall, J. Rutter \& J. Mills-Sheehy, Taking back control of regulation Managing divergence from EU rules, Institute for Government, mei 2021, p. 18.

56 Zie ook C.T. Dekker, 'Een gelijk speelveld voor EU-ondernemingen? De staatssteunregeling in de handels- en samenwerkingsovereenkomst tussen de EU en het VK', NtEr 2021/7, p. 195; en D. Collins, 'Standing the Test of Time: The Level Playing Field and Rebalancing Mechanism in the UKEU Trade and Cooperation Agreement (TCA)', Journal of International Dispute Settlement 2021.

57 Zie de Associatieovereenkomst tussen de Europese Unie en haar lidstaten, enerzijds, en Oekraïne, anderzijds (PbEU 2014, L 161/3), art. 64 (op het gebied van sanitaire en fytosanitaire maatregelen en maatregelen voor het welzijn van dieren) en art. 133 (financiële diensten).

58 Art. 387 lid 2 HSO op het gebied van arbeids- en sociale normen en art. 391 lid 2 HSO op het gebied van milieu en klimaat. 
sen (niet-toegestane) 'non-regressie' en (wel toegestane) 'divergentie' is hier uiteraard van groot belang. Wat het bestaande acquis betreft, mag het VK niet afwijken, maar voor toekomstige EU-wetgeving ligt dat natuurlijk anders. Maar ondanks het 'right to regulate' is het nog maar de vraag of het gebruikmaken hiervan door het VK altijd voordelig is. Studies laten zien dat 'even small changes can have profound consequences for British businesses'. ${ }^{59}$ De HSO-bepalingen over gelijk speelveld leggen dus de spanning bloot tussen enerzijds het verlangen van de Brexiteers naar autonomie op het gebied van regelgeving en handelsovereenkomsten met partners zoals de Verenigde Staten die soepelere normen hebben dan de EU, en anderzijds de bezorgdheid van de EU over wat zij als oneerlijke concurrentie beschouwt.

Een ander controversieel onderwerp tijdens de Brexit-onderhandelingen was de visserijsector. Hoewel deze sector voor beide partijen economisch onbelangrijk is, is de visserij een politiek gevoelige kwestie gebleken. Het gekibbel om een compromis dat door beide partijen thuis als een overwinning kan worden verkocht is zichtbaar in de relevante bepalingen van de HSO. In beginsel erkent de HSO de 'soevereine rechten van kuststaten' ${ }^{60}$ en herinnert daarmee aan de verschuiving in de positie van het VK van EU-lid en dus onderdeel van het gemeenschappelijk visserijbeleid naar derde land, en daarmee naar een onafhankelijke kuststaat met eigen controle over zijn wateren.

De HSO bepaalt dat de EU vijfenhalf jaar na de inwerkingtreding toegang tot de Britse wateren (territoriale zee en exclusieve economische zone) behoudt. Haar vangstquotum zal in deze periode echter met $25 \%$ afnemen. ${ }^{61} \mathrm{Na}$ afloop hiervan kan het VK jaarlijks beslissen hoeveel toegang het de EU wil verlenen. Tegelijkertijd bepaalt de HSO dat in het geval dat een partij (waarschijnlijk het VK) de toegang verder zou verminderen, de andere partij (waarschijnlijk de EU) compenserende maatregelen mag nemen 'die in verhouding staan tot de economische en maatschappelijke gevolgen van de wijzigingen van het niveau van en de voorwaarden voor de toegang tot de wateren'. ${ }^{62}$ Deze omvatten niet alleen het beperken van de toegang tot de eigen wateren, maar ook het opleggen van importtarieven op visserijproducten.

\section{De 'S' in de HSO: samenwerking op}

\section{niet-economisch terrein}

Naast handel en economische samenwerking bestrijkt de HSO ook samenwerking op een aantal andere terreinen. Het meest gedetailleerde hiervan is te vinden in deel drie over 'samenwerking inzake en justitie in straf-

59 Zie J. Reland, 'Divergency tracker: why divergence from EU law might mean more bureaucracy', UK in Changing Europe (beschikbaar via https:// ukandeu.ac.uk/divergence-tracker-bureaucracy-eu-law/). Zie voor deze effecten de 'regulatory divergence tracker': https://ukandeu.ac.uk/researchpapers/uk-eu-regulatory-divergence-tracker/.

60 Art. $493 \mathrm{HSO}$.

61 Art. 505 lid 5 HSO. Zie verder T.P.J.N. van Rijn, 'Europese en Nederlandse visserij na Brexit', NtEr 2020/3-4, p. 57

62 Art. 501 lid 1 HSO. zaken'. Hier moet men denken aan o.a. de uitwisseling van DNA en vingerafdrukken en het doorgeven en verwerken van personengegevens van passagiers, wederzijdse rechtshulp, en de samenwerking met de EU-agentschappen Europol en Eurojust. Vanwege Brexit maakt het VK niet langer deel uit van de ruimte van vrijheid, veiligheid en recht van de EU. Het had echter al een algemene 'opt-out' op dit gebied toen het nog lid was, met specifieke 'opt-ins' zoals deelname bij Europol. ${ }^{63}$

De post-Brexitsamenwerking op dit gebied is nu expliciet 'gebaseerd op de jarenlange eerbiediging door de Partijen en de lidstaten van de democratie, de rechtsstaat en de bescherming van de fundamentele rechten en vrijheden van personen', ${ }^{4}$ en 'de jarenlange inzet van de Partijen om een hoog niveau van bescherming van persoonsgegevens te waarborgen'. ${ }^{65}$ Dit deel beklemtoont met name respect voor het Europees Verdrag voor de rechten van de mens (EVRM). Dit deel van de HSO kan worden opgezegd indien het VK of een EU-lidstaat uit het EVRM stapt (de EU is zelf geen partij bij het EVRM). ${ }^{66}$ En het deel kan daarnaast worden opgeschort in het geval van 'van ernstige en systemische tekortkomingen' op het gebied van mensenrechten en bescherming van persoonsgegevens. ${ }^{67}$ Deze opties bestaan naast die met betrekking tot beëindiging of opschorting in geval van schending van essentiële elementen van de overeenkomst. Deze bewoordingen zijn aantoonbaar gemotiveerd door eerdere dreigementen en intimidaties door vooraanstaande Britse politici dat het VK zich uit het EVRM zou moeten terugtrekken. ${ }^{68}$

Daarnaast gaat deel vier van de HSO over 'thematische samenwerking' op de gebieden van gezondheidsveiligheid (gezien in het licht van 'grensoverschrijdende bedreiging van de gezondheid') en cyberbeveiliging. De bepalingen in dit deel blijven op het niveau van algemene beginselen, kaders voor samenwerking en de toegang van het VK tot informatiesystemen van de EU. De status van het VK als derde land komt ook hier duidelijk tot uiting. Zo geschiedt deelname aan het 'uitwisselen van informatie met betrekking tot oefeningen in verband met de beveiliging van netwerk- en informatiesystemen' ${ }^{69}$ alleen op uitnodiging van EU-organen en op basis van 'de autonomie van het besluitvormingsproces van de Unie'. ${ }^{70}$

Bovendien biedt deel vijf van de HSO een kader voor de toekomstige deelname van het VK aan programma's van de Unie, goed financieel beheer en financiële bepalingen. De programma's die openstaan voor het VK zullen

63 Zie P. García Andrade, 'Outside the Opt-out: Legal Consequences of the UK's Withdrawal from the EU for the External Action in the AFSJ', in: J. Santos Vara \& R.A. Wessel (red.), The Routledge Handbook on the International Dimension of Brexit, London: Routledge 2021, p. 104.

64 Art. 524 lid $1 \mathrm{HSO}$.

65 Art. 525 lid $1 \mathrm{HSO}$.

66 Art. 692 lid 2 HSO.

67 Art. 693 lid 1 en 2 HSO. Zie ook Łazowski 2020, p. 1133-1134.

68 www.knack.be/nieuws/wereld/theresa-may-dreigt-opnieuw-met-brexituit-mensenrechtenverdrag/article-normal-796005.html?cookie_ check=1637849985.

69 Art. 706 lid 1 onder b HSO

70 Art. 706 lid 1 HSO. 
in een nog overeen te komen 'Protocol I' worden vastgelegd. ${ }^{71}$ Als het VK wil deelnemen, zal het financieel moeten bijdragen 'aan de overeenkomstige financiering uit de begroting van de Unie'. ${ }^{72}$ Op 24 december 2020 is naar aanleiding van een gezamenlijke verklaring over dit onderwerp een ontwerp voor Protocol I opgesteld. Het bevat onder meer het ruimtevaartprogramma van de EU en het kaderprogramma voor onderzoek en innovatie Horizon Europa. ${ }^{73}$ Het VK is niet langer van plan deel te nemen aan het mondiaal, civiel satellietnavigatiesysteem Galileo van de EU. ${ }^{74}$ Hetzelfde geldt voor het studentenuitwisselingsprogramma Erasmus, dat het VK inmiddels door het eigen 'Turing-programma' heeft vervangen. ${ }^{75}$

\section{Wat staat niet in de HSO?}

Ondanks de brede dekking en innovatieve elementen van de HSO ontbreken er ook verschillende gebieden die de EU of het VK tijdens de onderhandelingen wilden opnemen. Relevante voorbeelden zijn de beslechting van geschillen tussen investeerders en staten, migratie en asiel en buitenlands beleid en defensie.

In tegenstelling tot CETA en andere EU-handelsakkoorden bevat de HSO geen hoofdstuk over de beslechting van geschillen tussen investeerders en staten (ook bekend onder de Engelse afkorting 'ISDS'). De politieke verklaring van 2019 bevatte een oproep om in een toekomstig handelsakkoord op te nemen dat 'de dienstverleners en investeerders van de partijen op niet-discriminerende wijze behandeld worden, onder meer wat vestiging betreft', ${ }^{76}$ wat niet hetzelfde is als een volwaardig hoofdstuk over ISDS. De HSO voorziet vervolgens 'slechts' in geschillenbeslechting tussen de partijen, dus de EU en het VK.

De HSO kent ook geen bepalingen over asiel en migratie. Hoewel de Britse regering dit onderwerp had willen opnemen in de overeenkomst, werden er geen specifieke toezeggingen op dit gebied gedaan. De EU en het VK hebben op 24 december 2020 echter een gezamenlijke politieke verklaring over asiel en terugkeer uitgevaardigd, waarin nota wordt genomen van 'het voornemen van het Verenigd Koninkrijk om met de meest betrokken lidstaten bilaterale gesprekken aan te gaan over geschikte praktische regelingen voor asiel, gezinshereniging van niet-begeleide minderjarigen of irreguliere migratie'. ${ }^{77}$ In juli 2021 ondertekenden het VK en Frank-

71 Art. 710 lid 1 en 2 HSO.

72 Art. 714 lid 1 HSO.

73 Verklaringen bedoeld in het besluit van de Raad betreffende de sluiting, namens de Unie, van de handels- en samenwerkingsovereenkomst en de Overeenkomst inzake beveiligingsprocedures voor de uitwisseling en bescherming van gerubriceerde gegevens, ST/8118/2021/INIT (PbEU 2021, L 149/2549).

74 www.gov.uk/guidance/uk-involvement-in-the-eu-space-programme\#galileoand-egnos.

75 www.trouw.nl/buitenland/britten-werken-aan-eigen-uitwisselingsprogrammavoor-studenten-ter-vervanging-van-erasmus bd01f4b8/.

76 Politieke verklaring waarin het kader wordt geschetst voor de toekomstige betrekkingen tussen de Europese Unie en het Verenigd Koninkrijk (PbEU 2020, C 34/1), punt 29.

77 Verklaringen bedoeld in het besluit van de Raad betreffende de sluiting, namens de Unie, van de handels- en samenwerkingsovereenkomst, rijk een gezamenlijke verklaring over de volgende fase van samenwerking bij de aanpak van illegale migratie. ${ }^{78}$ Bovendien vallen, ondanks de uitgebreide reikwijdte ervan, alle kwesties in verband met het buitenlands beleid en het veiligheids- en defensiebeleid van de EU niet onder de overeenkomst. Volgens de Europese Commissie wilde de Britse regering hierover niet onderhandelen. ${ }^{79}$ Het VK geeft de voorkeur aan een meer informele benadering wat betreft deze kwestie op basis van adhocoverleg met EU-lidstaten en de Europese Dienst voor extern optreden (EDEO). ${ }^{80}$ Zelfs een titel over 'politieke dialoog', sinds jaar en dag gebruikelijk in dit soort brede overeenkomsten, ontbreekt in de HSO. In 2017 had de Britse regering nog de ambitie getoond om het Britse EU-lidmaatschap te vervangen door een nieuw en diepgaand 'veiligheidspartnerschap', ${ }^{81}$ maar van die ambities is in de uiteindelijke overeenkomst niet veel terug te vinden. Sinds januari 2021 ontbreekt aldus een kader voor het VK en de EU om samen te werken op het terrein van buitenlands en veiligheidsbeleid. ${ }^{82}$

\section{Institutioneel kader en geschillenbeslechting}

Deze paragraaf analyseert het institutionele kader en het systeem voor geschillenbeslechting van de HSO. Binnen dit kader zullen de bepalingen van de HSO de komende jaren verder worden ontwikkeld en zullen toekomstige geschillen moeten worden opgelost. Als geen politieke oplossing kan worden gevonden, voorziet de HSO in veel gevallen in verplichte arbitrage.

\section{Institutioneel kader}

Vergelijkbaar met de associatieraden die deel uitmaken van andere associatieovereenkomsten, ${ }^{83}$ werd door de HSO een partnerschapsraad opgericht om zeker te stellen dat de overeenkomst correct wordt toegepast en geinterpreteerd. De partnerschapsraad bestaat naast het gemengd comité dat is opgericht om toezicht te houden op de uittredingsovereenkomst. ${ }^{84}$

p. 1477-1478.

78 UK-France joint statement: next phase of collaboration on tackling illegal migration, 20 juli 2021 (beschikbaar via www.gov.uk/government/publications/ uk-france-joint-statement-next-phase-of-tackling-illegal-migration/ukfrance-joint-statement-next-phase-of-collaboration-on-tackling-illegalmigration-20-july-2021).

79 https://ec.europa.eu/commission/presscorner/detail/nl/ip_20_2531.

80 Van Elsuwege 2021, p. 789.

81 Zie HM Government, Foreign policy, defence and development: A future partnership paper, 2017 (beschikbaar via https://assets.publishing.service.gov. uk/government/uploads/system/uploads/attachment_data/file/643924/ Foreign_policy_defence_and_development_paper.pdf).

82 Voor voorstellen voor zulke kaders van samenwerking op dit gebied, zie R.A. Wessel, 'Friends with Benefits? Possibilities for the UK's Continued Participation in the EU's Foreign and Security Policy', European Papers 2019, 4, p. 427.

83 Zie bijv. de associatieraad die is opgericht op basis van art. 460 Associatieovereenkomst tussen de EU en Oekraïne.

84 Art. 164 TA. Zie verder J.E. Larik, 'Decision-Making and Dispute Settlement', in: F. Fabbrini (red.), The Law \& Politics of Brexit - Volume Il: The Withdrawal Agreement, Oxford: Oxford University Press 2020, p. 191. 
De partnerschapsraad bestaat uit vertegenwoordigers van de EU en het VK. ${ }^{85}$ Omdat de HSO geen gemengd akkoord is, wordt de Unie door de Europese Commissie vertegenwoordigd. Niettemin mogen vertegenwoordigers van lidstaten deel uitmaken van de EU-delegatie in vergaderingen van de partnerschapsraad en van andere organen in het kader van de overeenkomst. ${ }^{86}$ De partnerschapsraad wordt gezamenlijk voorgezeten door een lid van de Europese Commissie en een vertegenwoordiger van de Britse regering op ministerieel niveau. De hoofdtaak van de partnerschapsraad is het toezien op de verwezenlijking van de doelstellingen en op de uitvoering en de toepassing van de HSO en eventuele aanvullende overeenkomsten. ${ }^{87}$ Daartoe kan de raad bindende besluiten nemen en aanbevelingen doen. Hij kan zelfs de overeenkomst op vastgelegde gebieden wijzigen. ${ }^{88}$ Een comité voor het handelspartnerschap en andere gespecialiseerde comités (zestien in totaal) handelen op basis van een delegatie van taken door de partnerschapsraad. ${ }^{89}$ Meer technische kwesties (over biologische producten, motorvoertuigen, geneesmiddelen en coördinatie van de sociale zekerheid) worden besproken in werkgroepen, bestaande uit vertegenwoordigers van zowel de EU als het VK. ${ }^{90}$ Alle besluiten worden bij consensus genomen..$^{91}$

Deze opzet loopt het risico nogal ondoorzichtig te worden. Aangezien de partnerschapsraad zelfs delen van de HSO kan wijzigen en de comités het eens zullen moeten worden over details die zijn overgebleven uit de onderhandelingen, is de vraag in hoeverre er publiek toezicht zal zijn op de procedures en uitkomsten. De covoorzitters kunnen overeenkomen dat de partnerschapsraad in het openbaar bijeenkomt en dat elke partij kan beslissen over de publicatie van de besluiten en aanbevelingen van de raad. ${ }^{92}$ Deel twee, titels IX en X van de HSO voorzien in transparantie en goede regelgevingspraktijken en samenwerking op het gebied van regelgeving in de vorm van de publicatie van wet- en regelgeving, procedures en administratieve uitspraken voor het publiek en het bedrijfsleven; een mechanisme voor vragen van het publiek; en de mogelijkheid van herziening en beroep van administratieve besluiten. ${ }^{93}$

Bovendien wordt in artikel 11 HSO voorzien in de mogelijkheid van een parlementaire partnerschapsassemblee, bestaande uit leden van de parlementen van de EU en het VK. Het niet instellen van een verplichte parlementaire vergadering - iets wat in andere associatieovereenkomsten gebruikelijk is ${ }^{94}$ - was op verzoek van

85 Art. 7 HSO.

86 Zie art. 2 Besluit (EU) 2020/2252 van de Raad.

87 Art. 7 lid $3 \mathrm{HSO}$.

88 Art. 7 lid 4 HSO.

89 Art. 8 HSO.

90 Art. $9 \mathrm{HSO}$.

91 Art. 10 lid 2 HSO.

92 Regel 10 inzake transparantie van het reglement van orde van de partnerschapsraad en de comités, in de bijlagen van de HSO.

93 Zie ook P. Birkinshaw, 'Brexit and the Trade and Cooperation Agreement: Endgame or Prolegomenon?', European Public Law 2020, 27, p. 242.

94 Vergelijk art. 467 Associatieovereenkomst met Oekraïne. de Britse regering. ${ }^{95}$ Bovendien moet een 'forum' het maatschappelijk middenveld betrekken bij debatten die relevant zijn voor de uitvoering van de HSO. ${ }^{96}$ Dit zijn echter vrij algemene oplossingen en het valt nog te bezien of technische details van de regelgeving waarover de comités overeenstemming hebben bereikt - met zonder twijfel een grote invloed op degenen die in specifieke sectoren actief zijn - in het openbaar zullen worden besproken.

De tijd zal leren hoe deze bestuursstructuur zal functioneren en zich zal ontwikkelen. Maar het is nu al duidelijk dat - samen met het systeem voor geschillenbeslechting waarop we hieronder ingaan - de HSO een systeem lijkt te hebben gecreëerd dat zal leiden tot voortdurende discussies en mogelijk zelfs nieuwe conflicten.

\section{Geschillenbeslechting}

De HSO omvat een relatief complex systeem van geschillenbeslechting. Er is noch een rol voor het Hof van Justitie van de EU noch voor de beslechting van geschillen tussen investeerders en staten. In plaats daarvan werkt de overeenkomst via arbitragetribunalen. ${ }^{97}$ De HSO voorziet in een standaardprocedure voor geschillenbeslechting, maar er is tevens een doolhof van uitzonderingen, en uitzonderingen op uitzonderingen, in verschillende specifieke contexten.98

Arbitrage is het laatste redmiddel. De eerste stap in de procedure is dat de partijen proberen 'het geschil op te lossen door te goeder trouw overleg te plegen om tot een onderling overeengekomen oplossing te komen'. ${ }^{99}$ Overleg binnen de hierboven beschreven politieke organen moet plaatsvinden binnen dertig dagen na de datum van levering van het verzoek door een van de partijen. ${ }^{100}$ Eerder noemden we al dat de HSO geen bepalingen bevat over geschillenbeslechting tussen staten en investeerders (ISDS). Dit is ook opmerkelijk omdat verschillende lidstaten (maar niet Nederland) nog bilaterale investeringsovereenkomsten hebben met het VK. ${ }^{101} \mathrm{Na}$ de Achmea-uitspraak van het Hof van Justitie van 2018 over de onverenigbaarheid van investeringsovereenkomsten tussen EU-lidstaten heeft het $\mathrm{VK},{ }^{102}$ net als de andere lidstaten, een politieke verklaring ondertekend waarin het zich ertoe verbindt intra-EU-investeringsovereenkomsten te beëindigen. ${ }^{103}$ In mei 2020 tekenden drieëntwintig lidstaten een overeenkomst over de beeindiging van bilaterale investeringsverdragen tussen

95 Łazowski 2020, p. 1140

96 Art. $14 \mathrm{HSO}$.

97 Art. 739-740 HSO.

98 Zie voor het toepassingsgebied van de geschillenbeslechtingsprocedures art. 735 HSO.

99 Art. 738 lid 1 HSO.

100 Art. 738 lid 4 HSO. Een spoedoverleg binnen twintig dagen is ook mogelijk 'zoals wanneer het bederfelijke waren of seizoensgebonden goederen of diensten betreft', art. 738 lid 5 HSO.

101 M. McCloskey, 'Safe Haven for Investors in (and Through) the UK PostBrexit?', ASIL Insights 2021, 25.

102 HvJ 6 maart 2018, C-284/16, ECLI:EU:C:2018:158 (Achmea).

103 Verklaring van de lidstaten van de Europese Unie van 15 januari 2019 over de juridische gevolgen van de Achmea-zaak en over investeringsbescherming. 
de lidstaten van de Unie. ${ }^{104}$ Maar toen was het VK al geen lidstaat meer. Na Brexit werden de afspraken met het VK 'extra-EU'-investeringsovereenkomsten en ze vallen daarom niet meer onder de Achmea-rechtspraak. Het systeem voor geschillenbeslechting tussen de EU en het VK in het kader van de HSO is beperkt tot conflicten tussen de partijen. De preambule van de HSO benadrukt het belang van regels voor geschillenbeslechting en handhaving van de verplichtingen uit de overeenkomst. Deze moeten echter 'in overeenstemming zijn met de respectieve rechtsordes van de Unie en van het Verenigd Koninkrijk, alsook met de status van het Verenigd Koninkrijk van land buiten de Europese Unie'. ${ }^{105}$ Achter deze formulering gaan fundamentele noties van autonomie schuil, die met name bij geschillenbeslechting voor beide partijen heilig zijn. ${ }^{106}$

De oprichting van een specifiek mechanisme voor geschillenbeslechting in de HSO kwam niet als een verrassing. Hoewel verwijzingen naar geschillenbeslechting in de hele overeenkomst te vinden zijn, worden met name in deel zes, titel I, de basisregels en de standaardprocedure vastgelegd. Het doel van die titel is vrij eenvoudig. Beoogt wordt

'een doeltreffend en doelmatig mechanisme ter vermijding en beslechting van geschillen tussen de Partijen over de uitlegging en toepassing van deze overeenkomst en aanvullende overeenkomsten op te zetten, teneinde waar mogelijk tot een onderling overeengekomen oplossing te komen'. ${ }^{107}$

Sommige onderdelen van de overeenkomst zijn uitgesloten van dit systeem ${ }^{108}$ in dat geval wordt voorgesteld dat de partnerschapsraad kan worden ingeschakeld om het geschil politiek op te lossen. ${ }^{109}$ Voor andere gebieden zijn specifieke geschillenbeslechtingsmechanismen ingesteld, zoals voor rechtshandhaving en justitiële samenwerking in strafzaken in deel drie, titel XIII. Het is ook belangrijk op te merken dat het systeem voor geschillenbeslechting uitsluitend zal worden gebruikt voor zaken die worden behandeld door de HSO. ${ }^{110}$

Als echter een geschil ontstaat over een mogelijke inbreuk op een verplichting van de HSO en 'een in wezen gelijkwaardige verplichting uit hoofde van een andere internationale overeenkomst waarbij beide Partijen partij zijn, met inbegrip van de WTO-Overeenkomst', ${ }^{111}$ dan moet eenmalig een keuze worden gemaakt voor een forum om het geschil te laten beslechten. ${ }^{112}$

104 Overeenkomst tot beëindiging van bilaterale investeringsverdragen tussen de lidstaten van de Europese Unie (PbEU 2020, L 169/1).

105 HSO, preambule, vijfde overweging.

106 Art. 737 HSO.

107 Art. 734 HSO.

108 Voorbeelden zijn onder meer strafrechtelijke handhaving, arbeids- en sociale normen en milieubescherming (inclusief klimaat) onder deel twee van de HSO

109 Art. 735 lid 3 HSO.

110 Art. $736 \mathrm{HSO}$.

111 WTO: World Trade Organization (Wereldhandelsorganisatie).

112 Art. 737 lid 1 HSO.
Wat houdt het mechanisme voor geschillenbeslechting tussen de EU en het VK in? De regels en procedures zijn vrij uitgebreid vastgelegd in deel zes en lijken op wat we kennen uit het geschillenbeslechtingssysteem van de Wereldhandelsorganisatie, maar dan zonder beroepsinstantie ('appellate body'). De ruggengraat van het systeem is de mogelijkheid om een 'arbitragetribunaal' in te stellen. Zo'n tribunaal bestaat altijd uit drie arbiters, die worden gekozen uit een door de Partnerschapsraad vastgestelde lijst van minimaal vijftien personen. ${ }^{113}$ Anders dan het TA voorziet de HSO niet in een rol voor het Permanent Hof van Arbitrage in Den Haag bij de selectie van de arbiters. ${ }^{114}$ Binnen 100-130 dagen levert het scheidsgerecht een tussentijds verslag op, dat door partijen moet worden gecontroleerd en becommentarieerd, waarna een definitieve uitspraak volgt maximaal 160 dagen na de instelling van het scheidsgerecht. ${ }^{115}$ De uitspraak is (volkenrechtelijk) bindend voor de partijen. Als een partij een verplichting uit hoofde van de overeenkomst niet is nagekomen, 'neemt die Partij de nodige maatregelen om onmiddellijk gevolg te geven aan de uitspraak van het scheidsgerecht, teneinde zichzelf in overeenstemming te brengen met de bestreken bepalingen'. ${ }^{116}$ Naast tijdelijke compensatie kan, net als bij het systeem van de Wereldhandelsorganisatie, handhaving de vorm aannemen van opschorting van verplichtingen onder de overeenkomst door de klagende partij. Deze maatregelen dienen te stoppen bij nakoming door de wederpartij. Voor geschillen over de mate waarin de uitspraak volledig is nagekomen, of over de evenredigheid van de vergeldingsmaatregelen, of over wat een redelijke termijn is om aan de uitspraak te voldoen, kunnen de partijen weer bij de arbiters terecht. ${ }^{117}$ Een substantiële schending van verplichtingen die zijn vastgelegd als 'essentiële onderdelen' van de HSO kan leiden tot het geheel of gedeeltelijk opschorten van de HSO. ${ }^{118}$ De essentiële elementen zijn gedefinieerd in artikel 771 HSO en hebben betrekking op de strijd tegen klimaatverandering, eerbiediging van democratische waarden en grondrechten, en non-proliferatie.

Zonder hier nader in te kunnen gaan op de verschillende uitzonderingen, ${ }^{119}$ is het belangrijk op te merken dat in sommige gevallen een van de partijen zogenoemde 'compenserende', 'corrigerende' en 'evenwichtsherstellende' maatregelen kan nemen zonder een voorafgaande uitspraak en autorisatie van een scheidsgerecht. Het

113 Art. 752, lid 1 HSO. De vijftien leden zijn onderverdeeld in drie groepen van ten minste vijf personen: een wordt door de EU benoemd, een door het VK, en samen komen ze overeen over een groep voorzitters die noch EU-burgers noch van Britse nationaliteit zijn. De Partnerschapsraad kan aanvullende lijsten opstellen (art. 252 lid 2 HSO). Zie voor de lijst Besluit (EU) 2020/2232 van de Raad van 22 december 2020 (PbEU 2020, L 437/182)

114 Art. 171 lid 5-9 TA.

115 Art. 745 HSO.

116 Art. 746 HSO.

117 Art $749 \mathrm{HSO}$

118 Art. 772 HSO.

119 Zie verder S. Peers, 'Analysis 4 of the Brexit deal: Dispute settlement and the EU/UK Trade and Cooperation Agreement', EU Law Analysis 8 januari 2021 (beschikbaar via http://eulawanalysis.blogspot.com/2021/01/ analysis-4-of-brexit-deal-dispute.html). 
is dan aan de andere partij om de wettigheid van deze maatregelen via arbitrage aan te vechten. Het gaat bijvoorbeeld om sommige, maar niet alle, bepalingen betreffende het gelijk speelveld, waaronder subsidietoezicht. Een partij mag hier zonder voorafgaande scheidsrechterlijke uitspraak:

'eenzijdig passende corrigerende maatregelen nemen indien er bewijs is dat een subsidie van de aangezochte Partij een aanzienlijk negatief effect op het handelsverkeer of de investeringen tussen de Partijen heeft, of indien er een ernstig risico op een dergelijk effect bestaat'. ${ }^{120}$

Bovendien kunnen 'vrijwaringsmaatregelen' ter bestrijding van 'ernstige economische, maatschappelijke of milieuproblemen van sectorale of regionale aard'121 eenzijdig door een partij worden genomen, zij het alleen na overleg met de andere partij en na het verstrijken van een wachttijd van één maand en na overleg met de wederpartij. ${ }^{122}$ Ook deze kunnen dan onderwerp zijn van een arbitrageprocedure. ${ }^{123}$

Deze procedures lijken over het algemeen in het voordeel van de EU te zijn, die zich zorgen maakt over oneerlijke concurrentie van een gedereguleerd VK en belang heeft bij het behoud van toegang tot Britse wateren. Onder de verschillende uitzonderingen van de HSO op de standaardprocedure voor geschillenbeslechting zou de EU niet hoeven te wachten op een uitspraak van een tribunaal. In plaats daarvan wordt de bal bij het VK gelegd om deze maatregelen aan te vechten.

Betekent dit dat er, naar wens van het $\mathrm{VK}$, geen rol is voor het Hof van Justitie? Wat de HSO zelf betreft, is dat het geval. Daarentegen mag niet worden vergeten dat het Hof van Justitie een rol blijft spelen op basis van het TA, dat het mogelijk maakt om geschillen tussen de EU en het VK voor te leggen aan het Hof van Justitie wanneer een vraag van het EU-recht op het spel staat. ${ }^{124}$ Dat dit geen theoretische optie is, blijkt uit het geschil dat ontstond over de interpretatie van het Protocol betreffende Ierland en Noord-Ierland. Amper zes weken na de inwerkingtreding van de HSO zette de Europese Commissie de eerste stap van een inbreukprocedure tegen het VK. ${ }^{125}$ Handhaving van de verplichtingen uit hoofde van het TA maakt ook de HSO-bepalingen weer relevant. Aanhoudende niet-naleving van het akkoord kan namelijk ook leiden tot opschorting van bepaalde verplichtingen uit hoofde van de HSO. ${ }^{126}$

120 Art. 374 lid 3 HSO.

121 Art. 773 lid 1 HSO.

122 Art. 773 lid 3 HSO.

123 Art. 773 lid 5 HSO.

124 Art. 174 TA. Zie verder Larik 2020, p. 191.

125 Zie Europese Commissie, Letter from Vice-President Maroš Šefčovič to David Frost, Brussel, 15 maart 2021 (beschikbaar via https://ec.europa. eu/info/sites/default/files/lettre_to_lord_frost_1532021_en.pdf).

126 Art. 178 lid 2 onder b TA.

\section{Conclusie en vooruitblik}

De komende jaren zal de HSO de hoeksteen vormen van het raamwerk van het 'post-Brexitrecht' tussen de EU en het VK. Zij is daarom veel meer dan een gewone bilaterale overeenkomst en dient als referentiepunt voor andere bestaande en toekomstige overeenkomsten tussen de EU en haar voormalige lidstaat. Naar aanleiding van een evaluatie van de implementatie van de HSO door de partijen zal de tekst vijf jaar na de inwerkingtreding worden herzien. ${ }^{127}$ Hiervoor is het aan de Partnerschapsraad en zijn verschillende comités om de leemten op te vullen en overeenstemming te bereiken over toepassing en uitvoering.

De HSO is belangrijk om de nieuwe relatie tussen de EU en het VK te begrijpen, maar biedt niet het hele plaatje. Zoals we hebben gezien wordt de neutrale term 'betrekkingen' gebruikt, waarbij zelfs ‘partnerschap’ zorgvuldig wordt vermeden in de verdragstekst, afgezien van de namen van enkele bestuursorganen. Het gebruik van deze wat afstandelijke terminologie is enigszins teleurstellend na bijna een halve eeuw van intensieve samenwerking. Hetzelfde geldt voor de keuze om de nieuwe samenwerking niet 'associatie' te noemen, ondanks het feit dat dit juist de wettelijke basis is aan de kant van de EU. De nieuwe relatie tussen de EU en het VK is uniek wat betreft de context, maar gaat niet verder dan de samenwerking die de EU heeft met een aantal derde staten die geen lid zijn geweest. De 'uitzonderlijke en unieke aard' ${ }^{128}$ van de HSO lijkt daarom meer te liggen in haar status en structuur als een complex akkoord dat niet de traditionele structuur volgt van andere raamovereenkomsten die de betrekkingen van de EU met derde landen regelen. ${ }^{129}$

De eerdere ambitie om een hechte, diepe en bijzondere samenwerking tot stand te brengen lijkt nu eerder een doel voor de lange termijn. Zoals we in dit artikel hebben laten zien zijn veel bestaande conflictgebieden niet opgelost, maar eerder verankerd in de overeenkomst. De HSO, samen met het Protocol betreffende Ierland/ Noord-Ierland en wat verder van toepassing blijft van het TA, is dus in de eerste plaats een kader voor het beheersen van spanningen en geschillen tussen de EU en het VK. In de HSO is dit zichtbaar in de rode lijnen van beide partijen tijdens de onderhandelingen: voor het VK autonomie en het uitsluiten van het Hof van Justitie, en voor de EU gedetailleerde regels om een gelijk speelveld te garanderen, verplichte procedures voor geschillenbeslechting en mogelijkheden om haar belangen jegens het VK af te dwingen. Als conflictmanagement soepel genoeg werkt om het vertrouwen tussen beide partijen in de loop van de tijd te herstellen en de vechtfase van Brexit achter zich te laten, kan de HSO inderdaad een belangrijke bijdrage leveren aan het opbouwen van een minnelijk toekomstig partnerschap. Als ze echter voornamelijk zal dienen om geschillen in

127 Art. 776 HSO.

128 Preambule van Besluit (EU) 2021/689 van de Raad van 29 april 2021.

129 Van Elsuwege 2021, p. 789. 
stand te houden en beide partijen te voorzien van politieke munitie om in hun eigen media te gebruiken, van visquota tot regelgeving tot mensenrechten, dan is vreedzame co-existentie het beste waarop we kunnen hopen. 